\title{
The role of humic substances in the speciation of metals in natural waters
}

\author{
Marina I. Dinu ${ }^{1, *}$ \\ ${ }^{1}$ Vernadsky Institute of Geochemistry and Analytical Chemistry (GEOKHI), Russian Academy of \\ Sciences, Moscow, 119991 Russia
}

\begin{abstract}
The paper analyzes currently applied methodological approaches to evaluating the speciation of metals in natural waters and presents literature data and original author's experimental results on the forms of metals in natural waters in various natural-climatic zones in Russia and other countries. Data are presented on the geochemical specifics of the distribution of metals between their forms in lakes RF.
\end{abstract}

\section{Introduction}

Analysis of natural waters for specification of metals is limited by the sensitivity and nonselectivity of most of the analytical techniques and by the complicated character of the material to be analyzed. The first attempts of analysis for coexisting species of elements in natural aquatic systems were undertaken in the late 19th century using then-available approaches of analytical chemistry [1,2].

The problem of studies of the distribution of elements between their forms is to estimate the mobility of these elements and their bioavailability. It is known that ionic (aqua-ionic) migration species are the most mobile for most metals, and hence, information on proportions of labile and nonlabile species is extremely important [3].

In addition to the foregoing characteristics of analysis, a number of interrelated natural factors controls the forms of metal ions: the geochemistry of soils in the catchment areas and the contribution of atmospheric precipitation. Depending on which water bodies are studied (whether these are rivers, lakes, or bogs), the contributions of various factors controlling concentrations of elements in the water may significantly vary. Atmospheric precipitation more strongly influences the chemical composition of the waters of small lakes as compared to the waters of rivers [3]. Lake waters are characterized by variations in the speciation of chemical elements and changes in the states of the components, which are controlled by the presence of natural reactive barriers [1].

One of the key components that define the state of elements in an aquatic system is organic (humic) compounds. Humic acids possess polymer stochastic properties, and the size and charge of molecules of these compounds directly depend on the physicochemical characteristics of the environment and the composition of the organic compounds (of the fulvate or humin subtypes, which are referred to as fulvic acid (FA) and humin acid (H)).

\footnotetext{
${ }^{*}$ Corresponding author: marinadinu999@ gmail.com
} 
A protective role of humic acid (HA) is not limited only to their complexation in solute and colloid states in waters. Many organic compounds can be concentrated in bottom sediments of water bodies [4] and thus offer the possibility of acquiring information on the speciation and the timing of accumulation of many chemical components.

Certain features of natural climatic zones in which organic compounds are formed are responsible for variations in the proportions of subfractions (humic and fulvic acids) in these compounds and for specific sets of functional groups and fractals in the structural matrix of the polymer. The allochthon compounds of natural waters are humic and fulvic acids (mixture of humic acids), whose molecular weights are lower than in soils. They are washed off the catchment areas according to their solubility and have the same proportions of active end-groups and aromatic structures as in soil humus. Correspondingly, each natural climatic zone is characterized by different protective properties of its natural waters with respect to various contaminants.

Extensive literature data devoted to this problem most commonly presents results of highly specialized studies of certain natural objects or a specialized technique (or techniques) developed by the authors and only very rarely offer information of more general nature, which reflects geochemical features and relations. Our work was centered on systematization of approaches currently applied in studying the forms of metals in natural waters and on identification of factors that are related to natural climatic zones and can affect the forms of metals in waters.

\section{Methodology applied to determination the specification of elements}

The forms of metals in waters are currently determined by means of computer simulations and experimental modeling. Each of these approaches makes it possible to more or less accurately evaluate the contribution of labile/nonlabile ionic forms. There are still very few papers presenting results of comprehensive studies, which make it possible to quantify the contribution of each of the methods.

The following two types of materials, which can be formed by simultaneous processes, are studied with the application of various methods:

1. various types of compounds of inorganic, organic, and mixed nature or complex coordination compounds of various stability (aqua-ionic species, complexes with inorganic ligands, etc.), which are studied using ion-exchange, chromatographic, and other methods;

2. size fractions (colloids, suspensions, real solutions, etc.), which are studied using techniques of successive filtration (nuclear filtration, ultrafiltration, membrane filtration, etc.).

The former variant of separation is relatively rapid because of the complicated nature and multicomponent composition of natural samples. Many papers on analytical techniques [5] mention partial losses of components due to chemical interaction of organic compounds of humic nature with resins.

The application of different ion-exchange resins in analysis of individual water bodies generally makes it possible to identify tendencies and estimate the roles of geochemical factors.

For example, some researchers using successive separation-filtration $(0.55 \mu \mathrm{m})$ techniques and ion-exchange columns estimated the distribution of metal ions in waters in northern lakes (in the Kola Peninsula, Norway, and Sweden) between aquatic species and complex forms [7]. The ion-exchange resins were identical in the operation principle (strongly and weakly active) but were different in chemical composition. Nevertheless, this only insignificantly affected the percentage of the complex species. 
For most northern water bodies, the authors of [6] suggested the proportions of various metals bound to organic compounds. Our results are generally consistent with literature data [1-3]. High complexation abilities were identified for iron, and the activities of other components are uncertain and strongly depend on the general chemical composition of the waters.

Our studies conducted using analogous methods allowed us to determine the distribution of a great number of chemical elements between various forms in lacustrine waters of the Kola Peninsula. It was determined that the degrees of chemical binding of iron, aluminum, and copper are generally higher than the deactivation of other metals, and moreover, high percentages of complex ions of these metals are favorable for a decrease in these degrees. We have determined that up to 30-40\% copper occurs as inorganic species because of the strong competition for ligands in certain lakes.

Physical laws underlie the other group of techniques (various types of filtration) and makes it possible to separate a species according to a certain feature, but the intermediate mixture of compounds (fraction) is only very rarely further studied with the application of other separation techniques. The distribution of metals over size fractions was studied in using various types of filtration. The influence of $\mathrm{pH}$ on the possible coagulation of elements was examined. These authors have determined the distributions of the elements for which the size of the molecules of the compounds does or does not depend on $\mathrm{pH}$.

Elements whose speciation depends on $\mathrm{pH}$ are transition metals, for which variations in the concentrations of hydrogen ions lead to changes in the degrees of hydrolysis and possible phase transitions. These elements are also susceptible to the redox cycle, which changes their oxidation states and complexation abilities.

The first group also includes organic-carbon contents, which is important for the further analysis of the protective properties of humic compounds and the migration of organic compounds from soils to waters. A decrease in $\mathrm{pH}$ suppresses the solubility of the soluble fractions of humic compounds. In other words, the leaching of humic fraction in acidic environments is most strongly suppressed, and this effect for fulvic acids is a little bit weaker [3].

We have estimated changes in the physicochemical properties of humic compounds at decreasing $\mathrm{pH}$. Our experimental data on the zeta-potential of fulvic acids separated from waters sampled in different natural climatic zones indicate that qualitative characteristics of organic compounds in different zones differently affect the surface charge of the highmolecular micelles of the fulvic acids. We have determined that fulvic acids in waters at chernozem territories are more stable than fulvic acids in soils. The molecules of fulvic acids separated from gleyic-podsolic soils are larger, and their positive charge is greater, which may be explained by that they contain more ions of Pearson's hard acids: sodium, potassium, aluminum, iron, etc. [5]. At external influence on the mesomer energy of end functional groups, variations in $\mathrm{pH}$, and the effect of transitional-metal ions not only induce charge redistribution (variations in the zeta potential) but also change the sizes of the molecules. When fulvic-acid samples separated from gleyic-podsolic and chernozem soils are acidified, the sizes of the molecules decreased by $20-25 \%$ on average due to the origin of much individual fragments. When metal ions were added, the zeta potential makes it possible to obtain information on the strength of the produced colloid.

Our data indicate that the effects of such metal ions as divalent copper, divalent lead, and univalent copper (at $\mathrm{pH}$ 5.5-5.6) shift the zeta potential of fulvic acids separated from soils toward negative values (from -15.0 to $-15.6 \mathrm{mV}$ ), whereas these values of fulvic acids from gleyic-podsolic soils are shifted toward values close to zero (about $0.5 \mathrm{mV}$ ). For trivalent iron and aluminum ions, the zeta potential of fulvic acids from gleyic-podsolic soils is increased to $+16.6 \mathrm{mV}$, and that for fulvic acids from chernozem approaches zero. Thereby $\mathrm{pH}$ also decreases (to 4.4). 
The molecular-weight structure of FA is also modified under these conditions: the molecular weight decreases by up to $30 \%$, i.e., the polymer becomes more fragmentary, and its electrical double layer separates each.

Ions unsusceptible to $\mathrm{pH}$ are those of alkali and alkali-earth metals and some of anionogenic type migration type, which is explained by a certain inertia of elements with respect to the degree of hydrolysis.

Mechanisms of speciation of metal ions and their size properties are suggested, based on studies of Karelian rivers and their tributaries using successive filtration ( $\mathrm{pH} \sim 7$ ).

It should be mentioned that speciation of metals can be reliably determined only with the application of combinations of physical and chemical techniques. In other words, any fraction with different molecule sizes should be additionally separated by chromatographic methods after each type of filtration. This enables data acquisition not only on the molecular size of the compounds but also on the qualitative composition. Unfortunately, the solutions of this problem are complicated by the absence of adequate standardization of the techniques: the absence of certified state standards for analysis of chemical species in waters, because of which simulated models for equilibria in natural waters are often applied instead of practically all estimation techniques.

\section{Geochemical characteristics of the origin of equilibrium concentrations}

\subsection{Hydrogeological Factors}

According to literature data [1-6] metals are transported in rivers mostly with particulate matter. Migration in a particulate form is favored by high $\mathrm{pH}$ and the presence of an adsorbent in the system. Particulate matter is the least dynamic in a water flow and contains more chemical elements than the solute form does. The origin of low-solubility compounds significantly limits possible variations in metal concentrations in natural waters. The following two physicochemical processes of interaction between the liquid and solid phase are usually discussed in the literature: the coagulation of colloids and the origin of suspensions and the desorption of metals. The former process is associated with a decrease in the dissolved metal concentrations, which is particularly important for the detoxication of heavy metals. Desorption and mobilization increase fluxes of solute species. The adsorption characteristics of metals depend on the types of the metal and adsorbent and on the physicochemical characteristics of the environment. In nature, $\mathrm{Mn}$ and $\mathrm{Fe}$ oxides and hydroxides and humic acids have high adsorption capacities with respect to metal ions and thus tend to decrease concentrations of ionic migration species of these ions.

Metals can be arranged in the following succession according to an increase in the role of particulate forms in migration (regardless of the composition of the adsorbent):

$\mathrm{Cd}(\mathrm{II})<\mathrm{Cu}$ (II) $<\mathrm{Mn}$ (II) $<\mathrm{Zn}$ (II) $<\mathrm{Pb}$ (II) $<\mathrm{Fe}$ (III).

It was proved that specific concentrations of metals in suspensions (normalized to a mass unit of the particulate matter, $\mu \mathrm{g} / \mathrm{kg}$ ) is less dependent on the hydrological regime than on the anthropogenic load [4]. According to their chemical activity in sediments, metal ions often define the following succession:

$\mathrm{Cr}$ (III) $<\mathrm{Fe}$ (III) $<\mathrm{Co}$ (II) $<\mathrm{Mn}$ (II) $<\mathrm{Zn}$ (II) $<\mathrm{Ni}$ (II) $<\mathrm{Pb}$ (II) $<\mathrm{Cu}$ (II).

It should be mentioned that adsorption processes more significantly compete with complexation and thus decrease concentrations of chemically bound (nonlabile) metals. 


\subsection{Geological Conditions at Watersheds}

Interesting data on geological prerequisites for the origin of fractions of different size elements in river and their tributaries in northwestern Russia (Karelia) are presented in [7$8]$.

The authors studied water enrichment in forms of different size of molecules for alkaline and acid rocks. For example, according to solute species are typical of alkali-earth metals in waters on soils of both types. Real solutions of iron ions in waters of two types are significantly different: the content of the fraction $<1 \mathrm{kDa}$ in acid rocks is twice as low as in alkaline rocks, and this is explained by the working $\mathrm{pH}$ of the system and the possibility of the origin of low-molecular complexes. Regretfully, studies of the effects of geological factors on speciation of chemical elements are still very scarce, but our experimental data and numerous local studies described in the literature seem to indicate that these factors do affect the migration forms of elements.

\subsection{Territories in Different Climatic Zones: Influence on the Inner Structures and Properties of Humic Acid}

Our experimental studies of the qualitative composition of humic and fulvic acids in various natural climatic zones (the samples were taken from soils on watersheds and natural waters) in the European part of Russia (ER) and western Siberia (WS) show significant differences in the concentrations of active functional groups of organic compounds [5].

Organic acids separated from soddy-porzolic soils in ER contain roughly the same concentrations of oxygen-bearing and aromatic plus aliphatic carbon fragments. Organic acids separated from soddy-porzolic soils in WS contain more nitrogen groups and are characterized by the dominance of Pearson's hard acids over soft ones. This is explained by the biochemistry of humus origin in WS soils and, perhaps, also by anthropogenic activities in the region. The variability of oxygen-bearing fragments (hydroxo, carboxyl, and carbonyl groups) is greater for HA in soddy-porzolic soils in WS that in samples from EPR, and this affects the acid-basic characteristics. Organic acids of chernozem in ER are dominated by aromatic and aliphatic hydrocarbon fragments over oxygen-bearing ones and contain nitrogen-bearing fragments of purine and pyrimidine nature and more carboxyl groups than in HC of chernozem in ER. The HA of chernozem in WS contain much Na ions, which is favorable for the shift of spectral bands corresponding to carboxyl groups. An important process affecting HA complexation with metals in soddy-porzolic soils in WS was determined to be gleization [which manifests itself in higher Fe(II) concentrations in the natural waters] and solonization for chernozems.

We have estimated the changes in the qualitative composition of humic compounds and fulvic acids after salts of metals were added to identify the most active functional groups and their specifics in different natural climatic zones. It was determined that the addition of salts of metals to samples of extracted organic acids makes it possible to distinguish specifics of mechanisms responsible for binding metals with functional groups of humic and fulvic acidsin different zones. Metal ions are characterized by different chemical affinity to individual functional groups of the samples. Iron (III) ions typically form bonds through the oxygen bridges of humic compounds of soddy-porzolic soils and through oxygen- and nitrogen-bearing fragments in chernozems in EPR. In HA samples from soddy-porzolic soils, interaction between iron ions is more strongly controlled by the oxidation state of this metal because of gleization processes. Iron(III) is bound dominantly through carboxyl groups, whereas iron(II) binds through nitrogen-bearing fragments and hydroxyl groups. Metals are bound to HA in chernozems in WS mostly by the mechanism 
of ion exchange because most of the active functional groups are "blocked" by sodium ions because of shaley lamination of the soils.

Ions of alkali-earth metals are Pearson's hard acids and are strongly bound through oxygen and nitrogen atoms, as is typical of both of the aforementioned regions of Russia. As shown by experimental data, $\mathrm{Cu}$ (II) and $\mathrm{Pb}$ (II) can bind with humus acid through softer centers: sulfur-bearing groups.

Based on our data, new successions of metal affinities to humic acid were composed with regard for specifics in different natural climatic zones. For example, comparison of the stability constants of metal complexes to humic acid in soddy-porzolic soils in ER can be described by the succession.

$\mathrm{Cu}(\mathrm{II})>\mathrm{Fe}(\mathrm{III})>\mathrm{Al}(\mathrm{III})>\mathrm{Ni}(\mathrm{II})>\mathrm{Zn}(\mathrm{II})>\mathrm{Pb}(\mathrm{II})>\mathrm{Co}(\mathrm{II})>\mathrm{Cd}(\mathrm{II})>\mathrm{Sr}(\mathrm{II})>\mathrm{Mn}(\mathrm{II})>$ $\mathrm{Cr}(\mathrm{III})>\mathrm{Ca}(\mathrm{II})>\mathrm{Mg}(\mathrm{II})$.

\section{Conclusions}

Analysis of literature data shows that there is still no unanimously accepted methodology for estimating the speciation of metals. Each of the currently applied analytical methods deals only with certain complexation types according to physical and/or chemical laws, and the simultaneous use of filtration and chromatographic techniques yields different results for the same waters.

At the same time, data on the distribution of metals between various species obtained by different analytical techniques reveal significant differences in the speciation of metals in waters in the European part of Russia and in western Siberia, which is explained by regional specifics in the geochemical prerequisites and by different types of the anthropogenic load, which control the functional differences of the humic acids and the overall chemical composition of the natural waters.

This study was financially supported by the Russian Science Foundation, Grant 18-77-00018.

\section{References}

1. D. S. Orlov, Soil Chemistry (MGU, Moscow, 1992) [in Russian]

2. A. I. Perelman, Geochemistry of Natural Waters (MGU, Moscow, 1983) [in Russian]

3. Yu. V. Alekhin, S. M. Ilina, S. A. Lapitskiy, and M. V. Sitnikova, "Results of a study of co-migration of trace elements and organic matter in a river flow in a boreal zone," Moscow Univ. Geol. Bull., 65 (6), 380-386 (2010)

4. M. I. Dinu, Influence of Functional Features of Humic matters on the Metal Speciation in Natural Waters (TyumGU, Tyumen, 2012) [in Russian]

5. C. D. Evans and D. T. Monteith, Water Chemistry Discussion. UK Acid Waters Monitoring Network: 10 Year Report (ENSIS Publishing, London, 2000)

6. P. N. Linnik and B. I. Nabivanets, Species of Metal Migration in Fresh Surface Wate (Gidrometeoizdat, Leningrad, 1986) [in Russian]

7. T. I. Moiseenko, N. A. Gashkina, and M. I. Dinu, Acidification of Waters: Sensitivity and Critical Loads (URSS, Moscow, 2017) [in Russian]

8. T. I. Nifanteva, P. Burba, O. Fedorova, V. M. Shkinev, and B. Yu. Spivakov, "Ultafiltration and determination of $\mathrm{Zn}$ and $\mathrm{Cu}$-humic substances complexes stability constant," Talanta 53, 1127-1131 (2001) 